\title{
A solution to the Crimean crisis: egalitarian shared sovereignty applied to Russia, Ukraine, and Crimea.
}

\section{JORGE EMILIO NÚÑEZ1}

\begin{abstract}
Conflicts in international relations have to do with sovereignty. There are various sovereignty disputes around the world that struggle between legal and political limbo, status quo and continuous tension with various negative consequences for all the involved parties. It is increasingly clear that the available remedies have been less than successful, and a peaceful and definitive solution is needed. The paper considers how distributive justice theories can be in tune with the concept of sovereignty and explores the possibility of a solution for sovereignty conflicts such as the Crimean case by application of Rawlsian methodology.
\end{abstract}

Keywords State sovereignty, sovereignty conflicts, distributive justice, Rawls

‘Crimea is Russian' some argue (Burke-White 2014). '[T]he United States and its European allies share most of the responsibility for the crisis', others maintain (Mearsheimer 2014). Yet some go even further and announce apocalyptically a new Cold War (Roskin 2014). Leaving aside these and other opinions, the fact is that in early 2014 Crimea became the centre of a crisis with Russia and Ukraine as leading actors in the conflict. President Yanukovych was driven from power, Russia seized control of Crimea, and a referendum followed. Ukraine and most of the Western world considered the measures invalid (Barry 2014). In addition to the Crimean "local" crisis in which we may recognise three agents, that is Crimea, Ukraine, and Russia, it is also a reality that this dispute has larger repercussions geographically, politically, and culturally speaking not only for the region but potentially with regards to the globe (Molchanov 2004).

While it is true that there is a crisis in the Crimean peninsula, and tension is evident between Russia and Ukraine, there is also a fair share of rhetorical argumentation adding unnecessary considerations within legal and political sciences that do not seem to offer any tangible way out. Given that the Crimean crisis is but one of

\footnotetext{
${ }^{1}$ Senior Lecturer in Law, Manchester Law School, United Kingdom, and Profesor de Derecho, Universidad Nacional de La Plata, Argentina. Address: 6.27 Sandra Burslem building, Lower Ormond Street, Manchester, M15 6HB, United Kingdom. E-mail: j.nunez@mmu.ac.uk
} 
many other sovereignty conflicts currently existent around the world, why not thinking of this particular dispute as an example towards peaceful multilateral understanding through dialogue and negotiations?

We are used to seeing and accepting as fact that in one territory there is one population governed by an ultimate authority, with a common legal bond or system of norms. What would happen if that one territory and population had two ultimate and hierarchically equal sovereigns (legally speaking) and, at the same time, two valid sets of norms? Would it be possible, for instance, that Israel and Palestine had sovereign authority at the same time over Jerusalem? Would it be possible that Argentina and the United Kingdom were at one time sovereign over the territory and population of the Falkland/Malvinas Islands? What about Russia and Ukraine having the same degree of sovereign power over Crimea? If the answer were positive, what would the consequences be-in terms of territory, population, government and law?

There are many cases that can be characterised as sovereignty conflicts in which international agents (namely, two sovereign States and the population of the third territory under dispute) claim sovereign rights for different reasons over the same piece of land. Crimea is but one amongst many other sovereignty disputes around the globe. Besides, these conflicts have a particular feature: their solution seems to require a mutually exclusive relation amongst the agents because it is thought that the sovereignty over the third territory can be granted to only one of them. Indeed, sovereignty is often regarded as an absolute concept-i.e. exclusive, and not shareable (Jackson 1999; MacCormick 1993; MacCormick 1999; Núñez 2017, 2015, 2014).

In light of this obsession with absolute, and rejection of shared sovereignty, long-standing disputes still continue to be presented around the world as a zero sum game, with many negative outcomes of different sorts (e.g. social struggle, bad governance, inefficient exploitation of natural resources, tension in international relations, and threat to local and international peace). Thus, while these conflicts are in principle confined to specific areas and start with negative consequences primarily for the local population, they tend quickly to expand to the regional and even the international level (e.g. effects on international price of oil, arms trafficking, terrorism, war).

International relations and legal and political scholarly literature offer various potential remedies that one could use to solve the problem. These include independence, self-determination and free association- to name a few. Although these remedies are useful in certain conflicts, they are futile in several others. Hence, these conflicts remain unresolved and in a legal and political limbo (Núñez 2017).

The challenge is to present the agents with a solution that can acknowledge their individual claims without disregarding those of their competing parties. However desirable, such a solution may seem Utopian. I propose 
to see these conflicts from a different yet broad perspective rather than as conflicts between separate and independent rights. Therefore, I view the problem as a distributive justice (Roemer 1996; Fleischacker 2004) issue following the work of Rawls (Rawls 1999). That is because distributive justice principles are a particularly appropriate tool to address sovereignty issues, just as they have previously been applied in assigning rights and obligations in other social institutions. As a consequence, reviewing different theories (e.g. 'first come, first served'; just acquisition; the principle of equality) may help us to resolve the problem (Rawls 1999). In this article, I argue that some sovereignty conflicts can be solved by using principles of distributive justice.

The article will start by characterising the stage for the negotiations and who may be able to act as a representative. Thereafter, these representatives will choose amongst a selection of options which one may be the once considered more suitable in order to solve sovereignty conflicts. Indeed, such a solution will be mainly a theoretical attempt to deal with the aforementioned disputes rather than an actual way of looking at political practicalities. That is to say, the following sections will leave aside the particular features of the Crimean crisis and embark on a theoretical exercise. The main reason to proceed in this manner is to eliminate any possible bias that otherwise may interfere with a peaceful solution. The final section of this paper will apply its findings to the Crimean case. It is important to make clear even with this application to the Crimean case the paper remains a theoretical experiment. Ergo, relevant nonideal issues-e.g. lack of compliance-will not be considered. It is assumed that all parties are reasonable and rational and want to resolve their conflict without violence. To put this in another way, this paper only claims it would be unreasonable to reject its outcome-i.e. the egalitarian shared sovereignty—should all ideal and assumed conditions were present (Núñez 2017).

\section{Setting the stage for the negotiations}

Any community or population consists of individuals who are different in many ways - pluralism, as Rawls says (Rawls 2003) - is a permanent feature that cannot be ignored. The international community does not escape from this, since it includes several agents of very different natures. Therefore, as in the case of civil societies in Rawls' Theory of Justice, I assume that the international society is constituted by several different agents who in their relations recognise some 'rules of conduct' and act upon them (Rawls 1999). However, only one kind of them, the State, has a specific characteristic: sovereignty. And even if the international community was only composed by sovereign States, they are different in many ways-e.g. strong and weak, developed and nondeveloped, populated and not populated, insular, peninsular, etc. It is for that reason that I also suppose that their interrelation is for 'mutual advantage' (Rawls 1999). But, as in any circumstances in which we have agents of 
different kinds - so the same is true of a community of States—relations amongst international agents introduce also identity and conflict of interests; and sovereignty conflicts are one of them. As a result, some criteria are needed for choosing the principles that can put a peaceful end to these conflicts.

As in any negotiation concerning different agents with a conflict of interest, we need to address a particular feature - pluralism - if we want to strive for a solution, even more if that solution is intended to be just and fair so as to secure a binding and respected agreement. Addressing this feature at the individual level, Rawls defines the 'circumstances of justice' as 'the normal conditions under which human cooperation is both possible and necessary' (Rawls 1999, p. 109). Then, he proceeds to divide them in objective characteristics, that is characteristics of the environment, physical and mental features of the participant individuals, their capacities and a state of moderate scarcity; and subjective characteristics, i.e. even though individuals may have similar needs and interests, each has an individual plan of life.

One of the first points that Rawls makes is that questions of distributive justice arise only under certain 'circumstances of justice', that is limited resources and limited altruism. In what is crucial for this article, there is also a common interest that is the cause of sovereignty conflicts and there are some 'circumstances of justice' that are particular to them. The territory under dispute — and all that it implies—is the one element around which the dispute is centred. In other words, what Rawls labels at the individual level as moderate scarcity or limited resources finds its parallel in sovereignty disputes in the non-sovereign third territory-i.e. the only 'thing' all the agents are claiming exclusive sovereignty over. To be more precise, what is scarce are the rights and obligations that sovereignty entails, in this article, over the third territory. Thus, what Rawls refers to as an individual's plan of life we may call a 'State plan of life'—each State's interest as a group is also represented by the exclusive rights it claims over the same piece of land.

In brief, there is a situation in which three populations coexist (two sovereign States and one non-sovereign group of people) and argue about their rights and obligations over the same territory. In the case sub examine, the ones in Russia, Ukraine, and Crimea give the three populations. There are limited resources or there is a moderate scarcity given by the claimed territory that each of them exclusively wants-i.e. Crimea. While these claimants could work together in a mutually advantageous way, they each have, as different groups of people, respectively their own collective 'plan of life' that is currently preventing them from doing this: their respective 'plans of life' in relation to the claimed territory are blocked by the other claimants, resulting in a zero sum game. 


\section{Formal constraints. A 'colourable claim'}

Before going into the negotiations to solve the sovereignty conflict we need to decide who will be able to be part of them — who is a legitimate claiming party. Therefore, both the claiming agents and the 'original position' as a whole are subjected to certain limitations. The agents will be limited in such a way that the right to claim is restricted to those who fulfil certain criteria, while other constraints secure the reasonableness of the procedure. The agents should have what I call a ‘colourable claim’ (Núñez 2017). A ‘colourable claim’ (in American English a colorable claim or colorable argument) is an expression used in the law of the United States to refer to a claim strong enough to have a reasonable chance of winning, that is the claim needs not actually result in a win. It is a non-frivolous argument either supported by reference to law or facts that may be proven in Court. That is to say, the represented populations must have a valid reason to claim sovereignty over the third territory, e.g. effective occupation ${ }^{2}$, consent by the other agent in the dispute ${ }^{3}$, consent by other States $^{4}$, and/or consent by the international community (Wright 1962). That reason should be 'colourable' enough to prove that their intended rights are at least sufficiently plausible to be acknowledged, and they can be based on any reasonable circumstances, e.g. political, historical, legal, geographical arguments to name a few. For example, in the case of the Falklands/Malvinas Islands dispute it would be unreasonable for Russia to participate in the negotiations in relation to their sovereignty since they do not have any colourable claim over that territory.

To put it in other words, a party will have a colourable claim if prima facie they have the right to claim, that is to say they appear to have a probable cause to support their intended right to claim. That is different from saying that they have a right to sovereignty. In the latter case, there is indeed an argument that has weight but that may be later overcome by another more pressing one. So, to have a colourable claim means having at least an argument that offers surface legitimacy that may or may not translate in the negotiations into granting sovereignty because it only secures the participation in them.

Because a colourable claim recognises surface legitimacy to claim sovereignty to a party, it does not need to be the case that the sovereign States or the population of the third territory have claims sufficiently equal in

\footnotetext{
2 The Island of Palmas Case (or Miangas), United States of America vs. The Netherlands, Permanent Court of Arbitration (1928) and The Legal Status of Eastern Greenland Case, Denmark vs. Norway, Permanent Court of International Justice (1933).

3 The Temple of Preah Vihear Case, Cambodia vs. Thailand (1962).

4 The Legal Status of Eastern Greenland Case, Denmark vs. Norway, Permanent Court of International Justice (1933).
} 
strength to give them roughly equal claims in respect of the third territory. In fact, one sovereign State could have a claim that entitled it to double the weight of the other sovereign State or that of the third population. That is because a colourable claim refers only to the right to claim sovereignty, and that is prior to any negotiations. It is indeed in the negotiations when the parties may discuss the weight of their claims. And that will be reviewed in due course in this article.

\section{Original position}

\section{Introducing the 'veil of ignorance'}

To recapitulate, we made clear why the competing parties (Russia, Ukraine, and Crimea) are going into negotiations, i.e. they have a conflict of interests in relation to a non-sovereign territory (Crimea) and want a just and fair way of solving it. Afterwards, we determined the conditions that should be fulfilled to be considered a claiming party and to take part in the negotiations, i.e. colourable claim. Now, what principles of distribution would the representatives of the three populations choose in relation to actual and potential rights and burdens over political, economic, legal, social and cultural aspects of the third territory? Would they opt for equality or for a difference principle for their distribution? Would they choose some other principle? The answer to these questions will depend upon the information the representatives will have, and in fact, they could be misled by such knowledge, hence the importance of defining the characteristics the original position in which the negotiations will be conducted.

The content of the original position is something we construct, and we construct it to reflect what we think is morally relevant and morally right; which is precisely what Rawls does. In tune with this, as Rawls does at the individual level, we have to define the characteristics of the original position in which the negotiations will happen in order to avoid any possible interference from factors that can cause bias and that may lead to a partly unjust or unfair outcome. Hence, we must use a procedure to eliminate the effect of these factors. The 'veil of ignorance' (Rawls 1999; Rawls 2003) that Rawls uses at the level of individuals will be applied in the international scenario, being the populations of the sovereign States and the non-sovereign third territory—all through their respective representatives - the subjects of such a model.

The fact that we follow Rawls and assume that the principles agreed on the first level-i.e. principles relative to certain institutions within a society—are just and fair does not mean that they will be automatically useful or 
even applicable in international relations (Núñez 2017). In other words, what is the information that is going to be available for the negotiators? In other words, how does the veil of ignorance work in sovereignty disputes?

\section{Adapting the 'veil of ignorance' to sovereignty conflicts: rationality of the parties and their representatives}

In order to have negotiations the three involved agents will have to select representatives within their communities (Núñez 2017). I will not dwell longer on detailing how the representatives are selected since for our purposes this process is irrelevant. The important point is that as the individuals comprising each of the three populations are rational and free-hence their consent has moral force - their representatives will also be free rational beings. Accordingly, the three populations - and their respective representatives - consist of free and equal rational beings who are mutually disinterested and who will honour the principles chosen in the negotiations regarding the sovereignty over the third territory, since they stand by their word.

It is assumed that the representatives do not know certain features. In other words, two limitations in relation to the representatives must be applied in order for the negotiations to start: firstly, for the negotiations to be just and fair the representatives will not know whom they represent but they know everything else-the history involved - who the three parties are, the difficulty of resolving sovereignty conflicts, and so on. By acting in this way they ensure that none of the agents is more or less advantaged or disadvantaged when choosing the principles upon how sovereignty will be allocated.

Secondly, concerning the representatives in their individuality, they are pure rational beings and as such they "are not allowed to know the social positions or the particular comprehensive doctrines of the persons they represent. They also do not know persons' race and ethnic group, sex, or various native endowments such as strength and intelligence [...]" (Rawls 2003, p. 15). Ergo, the representatives have to fulfil two necessary conditions, that is, the veil of ignorance applied to sovereignty conflicts means that: a) they do not know whom they represent; and b) they do not know a series of characteristics in respect to their own individuality. But they will have information available in respect to the two sovereign States and the third territory under dispute.

\section{Reasons leading to the principles of justice: The rule of maximin}

We assumed that three populations have selected representatives who will participate in negotiations to allocate the sovereignty over a territory. These representatives do not know which of the three populations they represent and certain characteristics about themselves; they only know of the existence of the territory which sovereignty 
has to be allocated, that the populations they represent have somehow a right to claim it-i.e. colourable claim - and the nature of the negotiations they are involved in. Then, in order to allocate the sovereignty of the third territory they know they have to decide which principles are applicable. For that reason, they will analyse the implications certain principles may have in such allocation. However, the first thing the representatives will have to agree upon is the procedure they will follow in the negotiations, the applicable rule.

In terms of the rule the representatives will apply in the negotiations it is highly possible they will choose "the maximin rule for choice under uncertainty" (Rawls 2003, p. 132). According to Rawls, it can be defined as follows:

"The maximin rule tells us to rank alternatives by their worst possible outcomes: we are to adopt the alternative the worst outcome of which is superior to the worst outcome of the others" (Rawls 2003, p. 133)

Bearing in mind how the original position in which the negotiations will take place has been characterised, it is reasonable that the representatives will have a prudent view making their choice — at least — conservative (Rawls 1999, in partic. pp. 130 and ff.). They apply maximin because it maximises the position of the worst off party, and since they may be the worst off party, that is what they would want to do. That is to say, the negotiations present a particular characteristic: uncertainty; and the that uncertainty has to do with the outcomes, who these people are, and more specifically who they represent. Indeed, sovereignty disputes are under an umbrella of incertitude since all of the agents start with a status quo and any decision in the negotiations may imply actions on either side that may result in gains but also losses for any of them. For instance, when the representatives see each of the proposed principles they know that in any case they will be deciding how to allocate the sovereignty over the third territory. However, they will also consider in their decisions that sovereign rights imply obligations. Thus, the representatives have to bear in mind that, although they may have information about the third territory, they do not know its factual features in the future and that they do not know whom they represent.

Indeed, maximin is not a general rule in cases of uncertainty. However, it is the desirable one in situations of high indeterminacy (Rawls 2003, p. 133), when the stakes are high and the worst position is tolerable. And the original position applied to sovereignty conflicts has features that translate in such a level of uncertainty that makes the maximin rule the option the representatives will choose. 
Whereas the status quo or the exclusive ownership of the third territory by one of the agents are valid options, they could literally result in either a loss of claimed rights for one or several claimants or permanent interference when deciding issues with consequences to all of them. If they wanted to have actual use of their claimed rights over the third territory they would have to make mutual concessions; in essence, they would have to 'slice' their rights into different portions or shares. It is possible that the agents in the conflict would prefer to be sure of sharing the benefits and burdens in respect to the third territory and the maximin rule would be the chosen one for the distribution of benefits and burdens - i.e. to share sovereignty. The issue now is to determine the nature and size of each particular share. It is for that reason that in the following it will be reviewed how different principles can be applied to sovereignty disputes.

\section{The negotiations: choosing a principle to allocate sovereignty}

The representatives in the original position will review a series of principles in order to allocate the sovereignty of the territory. A first limitation is given by the principles they will review as they will be offered a list or menu (Rawls 1999, p. 118). Before examining the principles of just distribution—as proposed by Rawls—I will focus the attention on the principle of 'just acquisition'. First, because it is usually the one presented by every agent involved in any sovereignty conflict to support its claim; second —as we will see, because it is the main reason why this kind of conflict remains in a legal and political limbo.

\section{Why 'just acquisition' cannot work}

Most, if not all, individuals and any sovereign State would think it obvious to apply Ulpian's maxim Suum cuique tribuere (Ulpian, Digest, 1.1.10) — to give to each his due or to distribute to each one his share—in the case of any type of distribution. What can be fairer than to give everyone what is due to them? However, to give to each his due is not a task without difficulties. Thus, it does not necessarily mean that to try to do this automatically produces the most just solution, because it may be hopelessly unclear what each person (or State) is entitled to.

Faced with the idea of applying any kind of principle based on a historical entitlement will confront the representatives with two main problems. First, they would need to agree upon a historical account: what actually happened, who was the first one to discover the territory, or to have a population there, etc. Second, they would need to decide what type of act makes their claimed rights just: the first one setting foot on the territory, the first 
one to have a permanent settlement, etc. Thus, in relation to the second problem, they would have to choose the theoretical background to decide what is just: res nullius or res communis, that is if the originally uninhabited territory belonged to no-one or everyone had a certain right over it. Besides, if there were conflicts in the past we would need to decide whether they were just or not and whether the just side won.

In relation to the first issue - the agreement on the historical account—each sovereign State taking part in a sovereignty conflict is certain that it has ultimate and highest right over the disputed territory, and the use and ownership of the third territory is due to them. As a consequence, sovereignty disputes do not move from a zero sum game. That is because, in order to determine the initial acquisition, we have to go back and resolve old historical claims only resulting in a practical matter: the competing agents are never going to agree on the 'correct' historical version of the events because the historical account is fundamentally controversial. Thus, it is common to observe in sovereignty differences that the involved agents usually support their claims through historical, legal, political, cultural or geographical arguments, even a combination of many of them. In other words, not only will be the dispute over what the facts are but also what the relative moral significance of those facts is. For example, one party will claim that whoever was the first one in the third territory is its owner and hence, its sovereign, and they were there first. But the opposite party disputes this, supporting their case with historical, legal, political, cultural and geographical evidence, and arguing either a) that they were there first, or b) that being first is not what makes acquisition just. Indeed, a party may argue that they were the first to to exploit its resources, or establish a community, and that should be the feature or element to be taken into account in order to determine when the acquisition is just. Because all the parties argue they were the first to do what gave them a right to the third territory, an approach based on a historical account is futile for providing a solution to sovereignty disputes and the conflicts continue endlessly, for example, arguments about the rightful sovereign of Jerusalem and surrounding areas have been present for generations. Since Biblical times the region has been centre of disputes in relation to the rightful settlement of different populations, for example, Genesis 14: 18-20 in which Jerusalem (or Salem) has already enemies. Should we go back to Biblical times in order to prove the current legitimate occupancy of the territory?

In addition to the historical account, even though we assumed the representatives finally agreed on the facts, it is not easy to see an agreement on how what is due to someone be determined, which way to acquire something is just and fair, and whether a certain way of acquiring the sovereignty over the third territory can be just and fair at the same time for two different agents. For instance, they may apply the just acquisition principle. But even 
with the application of the just acquisition principle sovereignty disputes produce endless conflict as we will see below.

The just acquisition principle has been previously related to territorial sovereignty since it has been maintained that "[a]mongst the objects to which this principle is meant to be capable of applying are portions of the Earth's surface, that is, areas of land" (Conway 1990). And that is exactly the aim of this project: to find a peaceful way of allocating sovereignty over non-sovereign areas of land. However, the principle of just acquisition is not the answer to resolve these issues. Its main pitfall is that the information required to apply this principle is not epistemically accessible in sovereignty conflicts, for example, how far back would we need to investigate so as to determine who the first inhabitants of the Falkland/Malvinas Islands were? What would happen in the case of extinct civilisations? What about cultures that were in Ancient Times nomadic?

The principle of just acquisition may work for individuals (Nozick 1999; Núñez 2017). For States, it may solve one problem, what one has to do, i.e. mix one's labour. But it leaves several other issues unresolved such as a) who did it first? b) how much do you own? (new problem, e.g. if you dig, can you claim that plot, the field or the whole island?), and c) who inherits the property: the inhabitants or their 'mother community'?

Any version of just acquisition will have the same problems: people will never agree on the relevant facts and the relevant test, and therefore all this principle would do is guarantee endless conflict. So, the representatives in the original position would reject it. Furthermore, the original position in which the representatives have to decide how to allocate the sovereignty over the third territory neutralises any argument in that respect: as the representatives do not know which population they are representing they would not be able to use historical entitlement as an argument; then, they would not have access to historical records (Rawls 1999, p. 160) or they would hypothetically not know how to apply them. Therefore, the theoretical device finishes with one of the main issues every sovereignty conflict encounters: endless discussion concerning historical entitlement that in most, if not all cases, is highly difficult to be demonstrated. Thus, since they would not agree to rely on a principle that guarantees endless conflict, it would be rejected as the principle to resolve these disputes. At the same time, it leaves all the agents with an equal footing to continue the negotiations since none of them can argue a better or more robust right over the claimed territory.

To sum up, the representatives of the involved agents in the conflict agree that the third territory does not belong to its inhabitants (no matter why) and that they will not argue their supposed historical rights They do not know which group they represent and therefore do not know which set of historical arguments to believe. So they 
recognise that making the resolution of this kind of dispute central is hopeless. In consequence, they accept that each of them has a right to some sovereignty over the third territory that is not the same as a right to be the actual and only sovereign. In addition to this, none of the representatives can obtain any special advantage for whomever they represent or can put them in a particular disadvantageous situation (Rawls 1999, p. 130). Consequently, the agreement should offer such a solution that not only is in the 'best interest' of just one of the parties but embraces in a way or another those of all the claimants. Therefore, they have realised that to share sovereignty is the best option for all of them (by application of the rule of maximin). Similarly, it is also the case that this is just under Rawlsian principles. That is because of the nature of the parties and the fact that each has a colourable claim, which we assume give them some legitimate interest in the sovereignty over the third territory. Then, and as they now need to work out the details of how to share sovereignty, they will explore the possibilities of applying these principles into the negotiations.

\section{The difference principle}

At first glance, the difference principle states that whoever is a potential recipient in any distribution will receive an unequal share of whatever will be divided. It applies a prioritarian rule that inequalities are unjustified unless they work to the advantage of the worst off members of a society (Rawls 1999, p. 54). In the following paragraphs I will review some considerations I believe the parties would have with regards the difference principle in the negotiations.

First, as the types of inequalities that can be permitted are not restricted (Rawls 1999, p. 55), some of them may go against the interests of the represented populations. To be more precise, the citizens amongst whom Rawls distributes hold nothing in advance of the distribution and the basic structure that comes out of the original position is meant to distribute all of their wealth and income fairly; the difference principle operates in advance of citizens holding anything. In our case, we have sovereign States and a third population who already possess wealth and who are likely to hold unequal amounts of wealth. In addition to wealth, all these parties will possess several other elements that are also likely to be unequal amongst them such as power, geographical location and others. Indeed, sovereignty is not merely a matter of wealth. So, when we think about dividing up whatever the third territory entails, we potentially have to think about what constitutes a fair allocation of additional wealth and any other elements that are attributes of sovereignty amongst parties who already have unequal holdings. We have to remember that the original position in this article is slightly different from the one Rawls uses. The original position is set up in such a way that the agreement reached has a target: the third territory and all that it 
implies in terms of rights and obligations, benefits and burdens. So, suppose that the two sovereign States are A and B and the third territory is C, and State A is much wealthier than State B and third territory C. Therefore, if $\mathrm{A}, \mathrm{B}$ and $\mathrm{C}$ are equal joint claimants to the third territory and all that it entails, the fact that $\mathrm{B}$ and $\mathrm{C}$ are poorer than $\mathrm{A}$ is an irrelevant consideration. Why should it be a relevant consideration if it is not relevant independently of the third territory? For example, if Argentina, the United Kingdom and the Falkland/Malvinas Islands have no responsibility for one another's material wellbeing simply as three international agents, why should they suddenly acquire that responsibility when it comes to their shared sovereignty over the islands? We are working with the assumption that $\mathrm{A}, \mathrm{B}$ and $\mathrm{C}$ have equal claims and that $\mathrm{A}$ has no obligation to sacrifice its equal claim to B or C just because they happen to be poorer. A simply does not have that sort of special responsibility to either $\mathrm{B}$ or $\mathrm{C}$.

Second, Rawls argues that the more advantaged will accept the principle because they need the cooperation of the least advantaged. But that is not true here. It fails to explain why the most advantaged population should agree to lower its benefits only because the least advantaged one needs to see its position improved. It may appear that this claim contradicts the veil of ignorance and the maximin but it does not. That is because once again we have to remember that sovereignty conflicts and sovereignty itself are complex. Indeed, the most advantaged would distribute the benefits with the least advantaged. And that seems fair, at least in Rawlsian terms. But what about the burdens? This is a pitfall in the application of the difference principle and not in relation to the veil of ignorance or maximin. Since it would imply that the inequalities in the distribution would be fair if they benefited the least advantaged, then the most advantaged party not only would have to share the benefits but also contribute more in terms of the burdens. And that seems unreasonable again.

Third, when we use the expression 'least advantaged' in sovereignty conflicts it is not clear in which sense or which criteria we would have to apply: would that be less economically developed agent, less human rights acknowledged, smaller territory, smaller population, less developed legal system, or others. We have two problems here: a) which feature or element we consider to determine the least advantaged; b) variability. In the case of the feature or element to be considered in order to determine the least advantaged, we have already said that sovereignty conflicts and sovereignty itself are indeed complex. It is true that Rawls himself applies the difference principle for material goods but not to rights and freedoms: the claim that different sort of features are at stake may not be conclusive. However, even in the case we only considered these features as material goods, sovereignty conflicts are still highly complex in the sense most of their features, if not all, imply both benefits and burdens. 
Thus, even if we agreed on the feature to be considered, to be the least and the most advantaged agent is a factual feature so it can vary in time. Then, the means and outcome would be variable in time too; so a question of amending the distribution would arise once the original position changed. Would that imply a change in the shares of sovereignty too?

To recapitulate, the difference principle does not imply that the worst off must be compensated, but that an unequal distribution is just, if it makes the worst off better off than they would be if no such distribution existed. Indeed, the principle can still be applied. This article does not claim that the principle cannot be applied. However, it is unsuited to sovereign inequalities. In that sense, the complications are numerous: a) it is problematic to determine who the least advantaged is and hence, there will be always two parties who are worst off, in different ways, in relation to the third claiming party; b) different parties will be the least advantaged with regard to different aspects of sovereignty because sovereignty and sovereignty conflicts are complex and imply both benefits and burdens in many different areas; c) the least advantaged will vary over time; and d) why would any of the parties be motivated to let everything work to the advantage of the least advantaged?

The equality or 'equal shares' principle

Strictly speaking, the principle of equality would see each individual with an equal share of whatever is to be divided. There is no consideration of their relative situations, that is it is not taken into account if they are the least or the most advantaged individuals in the society. From there, each and every agent in the dispute would have the right to the same relative portion of sovereignty. Everyone would be benefited equally, as well as having equal burdens, regardless of their State's internal or international situation, the level of effort put in, or the needs they may have. In the following paragraphs, I will present some considerations I believe the parties would make in relation to the equality principle.

What appears to be an easy solution — what is fairer than to give to everyone the same share? —offers immediate complications. A problem to be expected is that we have to distribute different goods. For instance, sovereignty covers several different aspects of any territory, population, government and law that imply both rights and obligations. Then, it seems not possible to go with equal shares sensu stricto. Moreover, even if that is what we wanted to do, in itself attractive, the term 'equal' has hermeneutic problems: what is an equal division? More specific to this paper: what is an equal division when dealing with sovereignty issues? (Otsuka 1998). 
There is then the first issue of how to interpret what is an equal share. However, that is not the only problem with the principle of equality applied in sovereignty conflicts. Even if we agreed upon criteria on how to define an equal share, as we have just pointed out, sovereignty implies an extensive range of rights and obligations that are difficult to be distributed following the same pattern such as defence system and natural resources, financial system against law, civil rights versus political rights, and more basic goods and services. Therefore, the principle of equality sensu stricto would not be enough.

A way to solve the difference amongst criteria to characterise an equal share can be defining them within the negotiation. That is, the representatives in the original position allocate equal shares of sovereignty to each of the three populations determining what they mean by the term 'equal'. Let us suppose that we considered sovereignty as constituted by 'lumpy goods', that is that sovereignty would be seen as composed by different 'goods' in several different areas such as territory, population, government, and law. Indeed, sovereignty might be also seen as composed by different goods that are qualitatively different in a way that makes some of them incommensurable rather than lumpy: the goods that form sovereignty lack a common quality in order to make a comparison or at least not all of them offer a common element or characteristic so as to be measured or compared. In any case, considering sovereignty as constituted either by lumpy goods or qualitatively different goods, we would need the parties to agree on determining what equal division means in this context.

There is still a further problem with the principle of equality and it is that of its application, especially with the actual utilisation of the share of sovereignty. It is often the case that the veil of ignorance leads to equality, but its application presents several issues: a) division of economic benefits; b) fulfilment of obligations; c) what to do with things or areas that, in principle, may not be shareable such as aspects of the law. In other words, and assuming that we solved the issue of determining what an equal division is, to apply equality sensu stricto would mean that unequal parties in many aspects received equal shares of the sovereignty over the third territory and all that it implies in terms of rights and obligations. Therefore, some of these claiming parties would find themselves with a share of sovereignty that did not provide them any benefit; for example, let us imagine the equal division of the defence of the third territory in the case sovereign State A was able to fulfil its duty but sovereign State B and third territory C had no defence power. Or the case of distribution of natural resources amongst State A that had the wealth and means for exploration and exploitation and State B and third territory C without even a chance to use their respective shares. Indeed, the application of equality sensu stricto is at least problematic and may result in an unfair outcome. 


\section{Preliminary requirements for a fair distribution}

To recapitulate, we have rejected just acquisition, the best interest of the child, the difference principle, and equal shares. In one way or another, the difference principle and the principle of equality offer both pros and cons. To be more precise, the principles are rejected not because of the principles themselves but the particular characteristics of sovereign conflicts and sovereignty itself and the way in which the original position has been set up. Indeed, sovereignty implies many aspects of many different levels. Not only is this translated in benefits but also burdens.

The solution reached must be one that, apart from being intuitively appealing in the negotiations under the veil of ignorance, can be applied when the veil is lifted in such a way that the three populations want to respect the agreement reached. Then, the solution must be somehow beneficial to the three agents, must recognise to an extent their claims and the result is not detrimental to any of the agents.

Thereby, and in order to succeed in choosing a principle to be applied for the allocation of sovereignty we must bear in mind some circumstances: a) when the veil of ignorance is lifted it is more possible than not that the claiming parties will be in very different situations in many areas; b) that the least advantaged party may be but does not need to be the population of the third territory; c) that sovereignty conflicts and sovereignty itself are complex: they imply both benefits and burdens in many different areas.

In order to address the issue of complexity we must first make clear how the parties will not use any agreement reached for their benefit only, that is, the agreement must not be a subterfuge for any form of domination from one or more claiming parties in relation to the other(s). That is because by application of the maximin rule it is plausible to think the representatives will have a cautious view in regards to the outcome. So, it is consistent with the veil of ignorance and the maximin that they may want some safeguards in order to secure their respective populations against any form of domination once the veil of ignorance is lifted.

Bearing in mind the previous discussions, it is reasonable for the representatives in the original position to agree on three basic points in order to share sovereignty before deciding how to do it (Núñez 2017):

First, it is prohibited to interfere with the internal or external affairs of any of the other agents.

Secondly, each agent will respect the liberties of the three populations; so no agreement reached can be interpreted in a way that curtails the basic non-political liberties of any of these populations (Rawls 1999 ToJ, p. 53; Núñez 2017). This point means that none of the agents is allowed to interfere in any way with the basic nonpolitical liberties of the inhabitants of any of the other parties. 
Thirdly, the agents will conduct their mutual relations in light of the principles recognised by the law of peoples (Rawls 1999 LoP, p 37). Following Rawls, it is reasonable to believe that the negotiators will agree on certain familiar principles already recognised by conventional and customary international law.

With these three pre-requisites agreed in this hypothetical situation, once the veil of ignorance is lifted the negotiators secure that the agreement is not a subterfuge for domination of any kind, that the individuals of each population safeguard their basic non-political liberties, and that the three agents are free and autonomous from each other-i.e. in the case of the third territory that does not mean independence, hence the use of the word 'autonomous'.

\section{The 'egalitarian shared sovereignty'}

The question at issue now is to decide, by respecting these two pre-requisites, how to share sovereignty. So, the issue is what would constitute a reasonable allocation of sovereignty over the third territory amongst sovereign States A and B and the third territory C as equal claimants - i.e. Russia, Ukraine, and Crimea, whose equality of claim is in no way affected by whatever other situation they already have; and that allocation has a target: the third territory (Crimea) and all that it implies in terms of rights and obligations. By acknowledging the circumstances in sovereignty conflicts, that is, different agents and an ample concept such as sovereignty, and the way in which the original position has been set up, a revised principle may offer comparable advantages that may make it a reasonable option.

Firstly, we must remind us of the fact that the representatives of the three parties are behind the veil of ignorance as characterised before in this paper. Hence, they are deprived of knowledge in regard to which party they represent. So, it is reasonable for them and likely to agree that each party has a right to participate in each aspect of sovereignty, regardless of their particular circumstances, i.e. their development or ability, because no one would want to be left out. In other words, they would agree that ideally they would have 'equal' shares of sovereignty over the third territory, which means that the three claimants would have equal standing or status. Therein, all three parties would have a right to participate and the decision making process in each case would be subject to egalitarian consensus: all the three parties should be granted an equal input into the decision making process. They all have the opportunity to present, and amend proposals in relation to every aspect of the sovereignty of the third territory.

A second point has to do with factual circumstances. The representatives would acknowledge that it would be hard to see how after lifting the veil of ignorance all the three parties had the same relative situations such as 
economic development, defence system, means for exploitation of natural resources, law, and so on. So it is reasonable to think that the representatives would agree that the degree of each party's participation would vary according to each party's ability to contribute. We also said in the previous paragraph that it is also reasonable to suppose that each party would as well have an interest in each aspect of sovereignty. Therefore, and bearing in mind these two circumstances - equal right to participate and different ability to contribute - it is reasonable to maintain that each party would have an interest in each aspect of sovereignty being handled in the most efficient manner.

A third point would be to determine the level of input and output of each party with regard to each objective/area/activity related to the sovereignty over the third territory. In principle, the representatives may think of distributing what benefits or rights each party would enjoy depending on the level of contribution that the party makes. Indeed, they acknowledge that some parties will be able to make a bigger or larger input than others. However, an immediate problem arises. The representatives would realise that by making the output dependant on the level of each party's input this could result in a subterfuge for domination. That is to say, the better off party contributing more towards one or more areas and therefore securing a larger stake while the other two parties were unable to make the same level of contribution that would be translated in an ad eternum share of benefits.

But if we added a proviso in order to make sure that the party with greater ability and therefore greater initial participation rights would have the obligation to bring the other two parties towards equilibrium, the proposal becomes reasonable. That is because it ensures the most efficient current distribution of rights and obligations but also ensures the party that currently benefits most has an obligation to bring the other two parties up to a position where they can contribute equally, that is, it has the burden to assist the other two parties to acquire the ability to contribute equally to that particular objective/area/activity of sovereignty over the third territory. Therein, the party with the greater ability in whatever area would agree to this because there is no other way of having the cooperation of the other two, and the other two parties would agree because this arrangement requires they receive something immediately and will eventually gain the ability to have an equal share, and they would otherwise get nothing.

It is true that the obligation is potentially onerous: what justifies the ascription of that obligation to the better off party? For example, if $\mathrm{A}$ is the stronger, and $\mathrm{B}$ and $\mathrm{C}$ are the weaker parties, is $\mathrm{A}$ obligated to raise the standards of B's and C's economies so that they can afford to invest in the exploitation of natural resources; or is it enough that A gives $\mathrm{B}$ and $\mathrm{C}$ a specific sum equivalent only to what $\mathrm{B}$ and $\mathrm{C}$ need to exploit resources on terms 
equal with $\mathrm{A}$ ? If $\mathrm{A}$ gives that sum to B and $\mathrm{C}$, are they obliged to spend it on exploitation, or can they spend it on something else and so forfeit any future claim to be assisted with the exploitation of natural resources? Why cannot B and C simply issue leases to commercial companies to exploit the resources on their behalf; why do they have to rely on help from A? What does the obligation imply in relation to unalterable inequalities, such as one state's being geographically closer to the third territory than the other?

The way in which the parties fulfil the final agreement or how the parties use the outcomes of the exploitation of their shares have to do with either practical matters that depend on each real scenario or with decisions pertaining internal sovereignty and therefore are out of the scope of this article. Similarly, to think of every possible factual difference amongst the parties such as geographical proximity would be out of the scope of an academic writing of similar nature, in particular when this is only a theoretical exercise.

In what matters the justification for the obligation owed by the more advantaged claimant, two clarifications must be made. Firstly, I do not claim that any obligation is prima facie owed amongst the parties. I believe the most advantaged party would accept the agreement or better said, it would be unreasonable for this party to argue it is not fair to accept it. Whether the most advantaged party actually accepts the arrangement or not is a different matter. Secondly, it is reasonable to believe that if the three parties in the original position agree on: a) equal standing; b) making the nature and degree of participation dependent on efficiency; and therefore c) at first the party with more 'input' will receive more 'output'; the more advantaged claimant—whoever that turns out to be - will accept to have an obligation to bring about equilibrium in the shares since, in the absence of that equilibrium, the more advantaged claimant would or could dominate the other claimants so there would be hardly a good reason for the other two parties to accept any other arrangement that somehow did not contain a degree of equilibrium. That is because anything less than shares in equilibrium would potentially imply a smaller share in comparison to those of the other parties. Therein, the bigger the share, the riskier the case for any of the parties to have more control on a particular issue pertaining sovereignty or the sovereignty of the third territory as a whole. This is directly linked to the idea of non-domination since the possible monopoly of power with regards to a particular issue pertaining sovereignty or the sovereignty of the third territory as a whole could degenerate into arbitrary power by the decisions being made mainly by the strongest party or in benefit only of the strongest party. In consequence, the freedom of the least advantaged parties with regards the choices they could make with their shares and the originally agreed equal standing could potentially be reduced to the 'rubber-stamping' of the decisions made by the strongest claimant. Therein, it is reasonable to believe that 
the representatives of the parties would find the equilibrium proviso a fair solution to safeguard the interests of the three populations involved.

This way of approaching sovereignty conflicts like the ones discussed in this article I will call egalitarian shared sovereignty and can be stated as follows. (table 1)

The egalitarian shared sovereignty solves sovereignty conflicts because it simply acknowledges the facts, because: a) that sovereignty conflicts and sovereignty are complex issues; b) that complexity is given by these issues being constituted by activities and goods that imply both benefits and burdens; and c) that the claiming agents are most probably in very different comparative situations in many senses.

We do not have the problem of defining equality because we are not referring to the parties but to the target, the third territory. All the parties receive equal shares of sovereignty since these shares are ideal (they only represent their right to equal benefits and the obligation to equal contributions and only in what is referred to the third territory).

Thereby, if they can make equal contributions, they will receive equal benefits. We do not even think of their relative situations as members of the international society. They are equal or not in as much as it is referred to the target, the third territory.

Coincidentally, if they cannot fulfil their obligations to the same extent, their returns will be affected. It is when the qualitative differences come into play. And they are referred to the situation of each of the parties in relation to a specific good in what matters only to the third territory.

To give an example, if a party A cannot defend the third territory because it does not have any means of defence, then it cannot contribute (so its return will be lessened). As we have two pre-requisites and a targeted agreement, the other two parties B and C will have to assist party A in as much as their assistance is needed to let party A have a similar contribution in regards to that specific good or activity (in the example, parties B and $\mathrm{C}$ will assist in the development of the means of defence of party A, but only in as much as it is necessary for the defence of the third territory).

Indeed, the egalitarian shared sovereignty provides for the legitimacy of initial differences in the benefits and burdens of the parties in a way that the equality principle does not. So when we reach the ultimate egalitarian shared sovereignty goal of equilibrium amongst the parties, there will be no problem in knowing what 'equal shares' require since these will be similar shares of each of the goods relevant to sovereignty (output) amongst three agents with similar level of use of their respective shares (input). I use the term 'similar' rather than 
'identical' when I refer to the final shares since there will be obviously some elements that because of factual restrictions or limitations cannot be equally or identically used, or at least not to the same extent in the literal meaning of these expression such as geographical proximity.

\section{Conclusion: Crimea, the Egalitarian Shared Sovereignty, and Utopia}

Following the previous paragraphs, I will now introduce a hypothetical situation in order to show how the egalitarian shared sovereignty works in the context of the Crimean sovereignty dispute. The aim of this example is to demonstrate how by acknowledging certain features and by applying the criteria mentioned before, a shared sovereignty model can work, at least in theory. Note that the following paragraphs will use an oversimplified view with reference to some key points usually controversial in any sovereignty conflict and that therefore are present in the Crimean case.

Consider a group of people living on a peninsula named Crimea. The majority of Crimean people are Orthodox Christian but there is a large majority of Muslims (there are some other minor religions represented as well). Although the territory is small in size, it is highly rich in natural resources. However, it is assumed here they do not possess the means for its exploration and exploitation and hence depend on third parties to do it. They do not have any means to defend the peninsula. At the centre of the Black Sea, Crimea faces directly Russia, Ukraine, Turkey, Georgia, Rumania, and Bulgaria. Finally, the sovereignty of the peninsula is currently claimed by the Russian Federation and Ukraine.

Ukraine is a medium size sovereign State with a medium size population, mainly Orthodox Christian. This country is situated linked to Crimea by land and it is also rich in natural resources. Ukrainians have their own means of defence.

Russia one of the largest sovereign States in the world in terms of territorial size, but not densely populated (although the population is larger in relation to those of Crimea and Ukraine). Russians are mainly Orthodox Christian with other several religious minorities. The territory is rich in natural resources. The Crimean people have very limited means to defend their territory. Geographically, they are located in the continent adjacent to Russia and Ukraine, so mainland Russia and Ukraine share with Crimea part of the continental shelf.

The following table gives a more visual account of the example. (table 2)

Crimea is strategically important for both Russia and Ukraine because of its location on the Black Sea, and hence the most advantaged in that respect (difference in Crimea's advantage). However, it is the least 
advantaged in terms of territorial and population size, and defence. Crimea is key in Ukraine's plans for energy independence and gas diversification strategy. The peninsula is important for Russia in many aspects such as natural resources and geopolitical location (for example, as a base for Russian navy).

Russia is the most advantaged in terms of wealth and defence (differences in Russia's favour), the least advantaged in terms of geopolitical location, and in particular less advantaged than Ukraine in relation to their geographical proximity to Crimea.

Ukraine is the most advantaged in terms of geographical proximity to Crimea (difference in Ukraine's favour), but less advantaged than Russia in terms of wealth and defence.

Before reviewing how the egalitarian shared sovereignty may work in this situation, let us see briefly how the principle of equality and the difference principle result when applied sensu stricto in this case.

If we applied equality strictly, they would all receive equal benefits and contribute equally towards the burdens. How would Ukraine fulfil its duty to defend Crimea? How would Crimean people defend themselves? The same could be said about natural resources because although Crimea, Russia, and Ukraine would receive the same share in terms of ownership, Crimean people would not have the means to exploit them. Several other implications could be drawn but we have already made a point. It is both unreasonable and unfair to expect three parties with different comparative situations in many different areas to contribute in an equal manner or to receive an equal return.

Nevertheless, to apply the difference principle in the same form may have similar consequences. Let us assume that overall Ukraine is the least advantaged in terms of natural resources, so they will receive a larger share. Crimea is less advantaged than Russia and Ukraine in terms of defence, so Russia will provide the means to defend the third territory. But Ukriane is less advantaged than Russia in terms of wealth, the natural resources in its territory are not part of the agreement so they are not under discussion, and they do not have means to defend the third territory to the same extent Russia does. Would they have to receive a larger share of the benefits resultant from the exploitation of natural resources in Crimea with means provided by Russia? Indeed, this seems unacceptable.

To recapitulate, we have two sovereign States Russia and Ukraine claiming sovereignty over Crimea, the third populated territory in our model. The three populations through their representatives agreed on sharing sovereignty over Crimea. They understand that they are dealing with many issues such as activities or goods, 
and these many issues imply both benefits and burdens. So, to ask all of them to contribute equally and receive an equal return is not the solution. Neither is it for the better off in any given activity to contribute more and the least advantaged in any other activity to receive a larger benefit. They may either lead to domination or to continuous assistance. And because they do also know that they will maintain the agreement under the three prerequisites, they keep their reciprocal non-interference and consider themselves reciprocally equals. In addition to this, they know it is a targeted agreement only referring to the third territory: this is not an agreement based on humanitarian reasons, domestic or global justice.

In order to make the egalitarian shared sovereignty work by acknowledging the many differences amongst the parties, we have to foresee the possibility that one party (or some of them) may contribute more and the other parties considerably less, so it would imply an unbalanced relationship that may indeed lead to a) domination or neo-colonialism; or b) continuous assistance.

Thereby, egalitarian shared sovereignty understood as a balancing principle amongst Crimea, Russia, and Ukraine— bearing in mind their differences_-implies:

Crimea, Russia, and Ukraine have all the same right to participate in every aspect of the sovereignty over Crimea. That is to say, they all have the opportunity to present and amend proposals in relation to every aspect of the sovereignty over Crimea (egalitarian consensus principle). Crimea shares in equal portions natural resources with Russia and Ukraine. Russia shares in equal portions the means for their exploration and exploitation with Crimea and Ukraine. And Ukraine, because of their geographical location, will grant special privileges for both Crimean and Russian enterprises only related to the exploitation of natural resources in Crimea (or any other activity but it must be related to Crimea).

Indeed, either Crimea or Ukraine may have issues in exploiting at the same level of efficiency as Russia their shares of natural resources. Hence, Russia must make sure that both the other agents reach the same level of exploitation or divide the benefits resultant amongst the three parties equally in the meantime, that is it is a targeted shared model.

The principle can be seen in a larger picture across the board with different activities. At first, the smaller and the larger the contribution, the smaller and the larger the return respectively. But as the agreement aims to avoid domination (secure non-interference) and has a target, it is to be expected a more evenly shared contributionreturn relationship amongst the parties will emerge in the long term. That is to say in the example, at first Crimea would be defended by Russia, and the latter would as well contribute to the exploitation of the natural resources in the peninsula (principle of efficiency). In principle, Russian would receive a larger share of the 
resultant benefits - the larger the contribution, the larger the return, and let us remember that Russia is contributing towards both defence and exploitation of natural resources in a larger manner than the other two agents (input-to-output ratio principle). This covers the burdens-benefits part.

But, as we have a targeted agreement, Russia must make sure both Crimea and Ukraine reach relatively the same level for the defence of the third territory and the exploitation of natural resources (equilibrium proviso). It is then when the contributions amongst the three will be more even as well as the returns.

Meanwhile, and in order to lessen the gap between contributions and benefits, Ukrainians could use the difference they have in their favour: geographically proximity means a more accessible bilateral commerce with Crimea, faster and possibly more effective response in case of international threat or attack, etc., things that Russia cannot offer.

Moreover, as the first and second pre-requisite grants non-domination and non-political liberties, different religious beliefs between could not be used for the advantage or disadvantage of any of the populations. That is because they are in a certain order of priority. This principle is applicable only to sovereignty over the third territory and to what concerns the third territory (and all that this implies). Thus, the principle and the prerequisites are lexically ordered (Rawls 1999, pp. 53 in fine and 54 supra) both mutually and in relation to the egalitarian shared sovereignty. In other words, no transgression of: a) non-domination or non-interference; b) the basic non-political liberties; and c) the principles recognised by the law of peoples, is allowed under any excuse or reason even if that means not fulfilling the 'egalitarian shared sovereignty.'

The lexical order dictates the priority amongst the pre-requisites and the principle if there is a conflict in practice. Indeed, the pre-requisites and the 'egalitarian shared sovereignty' are intended as a single conception and not to work individually. However, reality may show instances in which to apply the principle could go against one or both pre-requisites. Therefore, the lexicographic or lexical preference ordering applies. That is because the agents will have multiple criteria motivating their choices. As they will have a ranking of priorities, the choice amongst the different alternatives will follow the highest criterion. Inversely, by respecting the egalitarian shared sovereignty we know the agents will take into account both pre-requisites.

The main reason to proceed this way is to secure a real 'equal footing'. Indeed, as a result of the lexical order basic rights will only be compared with other basic rights, powers and prerogatives with other powers and prerogatives, and so on. Thereby, arrangements that could imply trading basic non-political liberties for, for example, the exploitation of natural resources, could be avoided. So, none of the agents could use their relative better position at the expense of any of the other parties. 


\section{References}

Barry, M. (2014) 'The Loss of Crimea, How Much Does Ukraine Lose, and How Much Does Russia Gain, a Computable General Equilibrium Model', Journal of Global Peace and Conflict, 2.

Burke-White, W. (2014) 'Crimea and the International Legal Order', Survival: Global Politics and Strategy, 56.

Conway, D. (1990) 'Nozick’s Entitlement Theory of Justice: Three Critics Answered', Libertarian Alliance, Philosophical Notes, 15.

Fleischacker, S. (2004) A Short History of Distributive Justice (Harvard, Harvard University Press).

Jackson, R. (ed) (1999) Sovereignty at the Millennium (Oxford, Blackwell Publishers).

Kohm, L. (2008) 'Tracing the Foundations of the Best Interest of the Child Standard in American Jurisprudence', Journal of Law and Family Studies, 10.

MacCormick, N. (1993) 'Beyond the Sovereign State', The Modern Law Review, 56.

MacCormick, N. (1999) Questioning Sovereignty: Law, State, and Nation in the European Commonwealth (Oxford, Oxford University Press).

Mearsheimer, J. (2014) 'Why the Ukraine Crisis is the West's Fault', Foreign Affairs, 93.

Meyer Greene, T. (ed) (1929) Selections of Immanuel Kant (London, Charles Scribner's Sons Ltd.).

Molchanov, M. (2004) 'Ukraine and the European Union: a Perennial Neighbour?', Journal of European Integration, 26.

Núñez, Jorge E. (2017) Sovereignty Conflicts and International Law and Politics: A Distributive Justice Issue (Routledge, Taylor \& Francis Group).

Núñez, Jorge E. (2016) 'Sovereignty Conflicts and the Desirability of a Peaceful Solution: Why Current International Remedies are not the Solution', in Frenkel (ed) (2016).

Núñez, Jorge E. (2015) 'Sovereignty Conflicts as a Distributive Justice Issue: The Egalitarian Shared Sovereignty and a New Mode of Governance for Crimea', (in Russian: Конфликты суверенитета как проблема распределяющей справедливости: уравнительно разделенный суверенитет и новый режим 
Page $\mathbf{2 6}$ of $\mathbf{2 6}$

управления в Крыму), in Legal Theory: Comprehension of sovereignty in Russia, Western Europe, and the USA in the Conditions of Globalization. Ivanovo State University.

Núñez, Jorge E. (2015) ‘Sovereignty Conflicts as a Distributive Justice Issue’, in Frenkel (ed) (2015).

Núñez, Jorge E. (2015) 'About the Impossibility of Absolute State Sovereignty: The Middle Ages', International Journal for the Semiotics of Law 28.

Núñez, Jorge E. (2014) ‘About the Impossibility of Absolute State Sovereignty: The Early Years', International Journal for the Semiotics of Law, 27.

Núñez, Jorge Emilio. (2011) 'The Origins of Sovereignty in the Hellenic World', in Frenkel (ed) (2011).

Otsuka, M. (1998) 'Self-ownership and Equality: a Lockean Reconciliation', Philosophy and Public Affairs, 27.

Rawls, J. (1999) 'The Law of Peoples', Critical Inquiry, 20, 1.

Rawls, J. (1999) A Theory of Justice, Revised Edition (Oxford, Oxford University Press).

Rawls, J. (2003) Justice as Fairness (Harvard, Harvard University Press).

Roemer, J. (1996) Theories of Distributive Justice (Harvard, Harvard University Press).

Roskin, M. (2014) 'The New Cold War’, Parameters, 44.

Wright, Q. (1962) 'The Goa Incident' The American Journal of International Law, 56. 